\title{
Unraveling the Dichotomy of Enigmatic Serine Protease HtrA2
}

\author{
Ayon Chakraborty ${ }^{1}$, Roshnee Bose ${ }^{1}$ and Kakoli Bose ${ }^{1,2 *}$ \\ ${ }^{1}$ Integrated Biophysics and Structural Biology Lab, ACTREC, Tata Memorial Centre, Navi Mumbai, India, ${ }^{2}$ Homi Bhabha National \\ Institute, BARC Training School Complex, Mumbai, India
}

Mitochondrial high-temperature requirement protease A2 $(\mathrm{Htr} A 2)$ is an integral member of the HtrA family of serine proteases that are evolutionarily conserved from prokaryotes to humans. Involvement in manifold intricate cellular networks and diverse pathophysiological functions make HtrA2 the most enigmatic moonlighting protease amongst the human HtrAs. Despite perpetuating the oligomeric architecture and overall structural fold of its homologs that comprises serine protease and regulatory PDZ domains, subtle conformational alterations and dynamic enzymatic regulation through the distinct allosteric mode of action lead to its functional diversity. This mitochondrial protease upon maturation, exposes its one-of-a-kind N-terminal tetrapeptide (AVPS) motif that binds and subsequently cleaves Inhibitor of Apoptosis Proteins (IAPs) thus promoting cell death, and posing as an important molecule for therapeutic intervention. Interestingly, unlike its other human counterparts, HtrA2 has also been implicated in maintaining the

OPEN ACCESS

Edited by: Ashis Biswas,

Indian Institute of Technology

Bhubaneswar, India

Reviewed by:

Barbara Cellini,

University of Perugia, Italy

*Correspondence: Kakoli Bose kbose@actrec.gov.in

Specialty section: This article was submitted to Protein Biochemistry for Basic and Applied Sciences, a section of the journal Frontiers in Molecular Biosciences

Received: 29 November 2021

Accepted: 14 January 2022

Published: 03 February 2022

Citation:

Chakraborty A, Bose $R$ and Bose $K$ (2022) Unraveling the Dichotomy of

Enigmatic Serine Protease HtrA2.

Front. Mol. Biosci. 9:824846.

doi: $10.3389 /$ fmolb.2022.824846 mitochondrial integrity through a bi-functional chaperone-protease activity, the on-off switch of which is yet to be identified. Furthermore, its ability to activate a wide repertoire of substrates through both its $\mathrm{N}$ - and $\mathrm{C}$-terminal regions presumably has calibrated its association with several cellular pathways and hence diseases including neurodegenerative disorders and cancer. Therefore, the exclusive structural attributes of HtrA2 that involve multimodal activation, intermolecular PDZ-protease crosstalk, and an allosterically-modulated trimeric active-site ensemble have enabled the protease to evolve across species and partake functions that are fine-tuned for maintaining cellular homeostasis and mitochondrial proteome quality control in humans. These unique features along with its multitasking potential make HtrA2 a promising therapeutic target both in cancer and neurodegeneration.

Keywords: HtrA2, allostery, PDZ domain, enzyme, apoptosis, cancer, neurodegradation

\section{HISTORY AND BACKGROUND}

The highly conserved high temperature requirement A (HtrA) family of serine proteases that perform a multitude of diverse physiological functions, constitute the core group of cellular proteases (Page and Di Cera, 2008). A complex oligomeric architecture (spanning from trimeric to 24-meric forms), which include an atypical $\mathrm{N}$-terminal region, a conserved protease domain along with one or two C-terminal PDZ (postsynaptic density of $95 \mathrm{kDa}$, disc big, and zonula occludens 1) domains in each monomeric subunit make this family stand out among all other serine proteases (Clausen et al., 2002). Interestingly, the $\mathrm{N}$-terminal regions of $\mathrm{Htr} A$ s exhibit significant sequence, size, and structural variability that encompass single transmembrane domain (prokaryotic DegS and human HtrA2), 
signal sequences, insulin-like growth factor-binding domains, and serine protease inhibitor domains (human HtrA1, HtrA3, and HtrA4) implicating intra- and inter-species functional divergence. Furthermore, their catalytic activity that can be allosterically tuned through an intricate rheostatic on/off switch as well as the modulatory protein-protein interaction domain(s) aka PDZ, has garnered much attention for their immense translational possibilities.

Interestingly, unlike eukaryotes and bacteria, archaean genomes are devoid of HtrA homologs (Koonin and Aravind, 2002). Although, all sequenced Nematoda genomes including the model organism Caenorhabditis elegans lack HtrA-like genes, they do encode PDZ-containing proteins (Koonin and Aravind, 2002) thus underscoring the functional relevance of this regulatory domain in various cellular pathways. While bacterial HtrAs have been demonstrated to be involved in protein quality control processes such as protein folding, stress response, and degradation of misfolded cell envelope proteins (Clausen et al., 2002), this function is manifested in their mammalian counterparts through the elimination of misfolded proteins including growth factors, regulation of cell proliferation, migration and apoptosis (Grau et al., 2005; Hou et al., 2005; Kapri-Pardes et al., 2007; Moisoi et al., 2009).

Among the four human HtrAs (HtrA1-4) that have been identified to date, HtrA2 has been most widely studied due to its enigmatic structural characteristics and profound functional relevance. While HtrA2 is found in the mitochondrial intermembrane space (IMS), its paralogs HtrA1, 3, and 4 are mostly found in the secretory process. Despite similar overall structural signature and conserved protease and PDZ domain architecture, these enzymes show a significant divergence in their $\mathrm{N}$-terminal regions that might be essential for catering to their distinct functional properties For example, the N-terminal regions of $H \operatorname{trA} 1,3$, and 4 include secretory signals, along with insulin-like growth factor binding motifs and Kazal-type $S$ protease inhibitor domains, while HtrA2 contains a mitochondrial localization signal (Figures 1A,B).

HtrA2, with a pyramid-shaped trimeric ensemble, is unique among its peers being the only known mitochondrial protease with a PDZ domain that identifies exposed hydrophobic regions of misfolded proteins (Li et al., 2002; Clausen et al., 2011; Singh et al., 2011). Furthermore, with the triggering of apoptotic signal, mature HtrA2 gets released from the mitochondrial IMS into the cytosol at the expense of its first 133 amino acid residues (Figure 1B). This series of events exposes an N-terminal tetrapeptide motif (AVPS) that binds to the Inhibitor of Apoptosis Proteins (IAPs) and abate their inhibition on caspases thus promoting apoptosis. Furthermore, HtrA2 is known to participate in apoptosis through both caspasedependent and independent pathways, the latter through its serine protease activity (Hegde et al., 2002; Martins et al., 2002; Verhagen et al., 2002). Apart from its prominent role as a proapoptotic molecule, its involvement in neurodegenerative disorders has also been established through a missense mutation (Ser276Cys) in transgenic mice that exhibited motor neuron degeneration 2 (mnd2) implicating a Parkinsonian phenotype in humans (Jones et al., 2003). Further functional and clinical studies established HtrA2's involvement in several neurodegenerative disorders (Inagaki et al., 2008; Kang et al., 2013; Wagh and Bose, 2018; Bose et al., 2021).

\section{STRUCTURAL FEATURES OF HtrA2}

Several efforts over the past decade have been made to capture the structural complexity of this proapoptotic enzyme from various perspectives. Shi and co-workers first provided the snapshots of the inactive (S306A) substrate-unbound form of mature HtrA2 in three-dimensional space ( $\mathrm{Li}$ et al., 2002). The structural data showcased a trimeric pyramidal architecture with the short $\mathrm{N}$-terminal regions upholding the oligomeric ensemble through van der Waals interactions, while three PDZ domains at the base encapsulated the active-sites of the protease domains. The protease domain that embeds a hydrophobic active-site pocket with the catalytic triad (Ser306, His198, and Asp228) forms a compact structural fold comprising seven $\alpha$-helices and $19 \beta$-strands. Surrounded by several regulatory and specificity loops, this domain is positioned deep within the oligomer at $25 \AA$ above the base of the pyramid (Figure 1C) suggesting the requirement of substantial conformational changes for substrate binding and subsequent cleavage. The core of the pyramid is flanked by the regulatory $\mathrm{PDZ}$ domains that recognize and bind to the C-terminal region of their interacting partners. This is achieved through the canonical PDZ binding groove (YIGV) that is integrated into the PDZprotease domain interface. The structural study also demonstrates that several non-covalent interactions in the substrate-unbound state keep the protease domain in its 'closed' conformation, through inhibitory interference from the surrounding PDZ domains.

Although, this structure provided an excellent overview of the HtrA2 structure, this substrate-unbound form of the protease failed to explain the underlying dynamics of its mode of activation. Most importantly, the model's inability to enumerate the necessity to have a trimeric structure for its enzymatic functions as well as the mode of its distal allosteric regulation, impelled scientists to unravel the minutiae of its interactions from a more physiological as well as quantitative perspectives.

\section{ACTIVE SITE CONFORMATION AND MULTIPLE ACTIVATION MECHANISMS OF HtrA2}

The pre-defined conserved domains of HtrA2, along with its regulatory (L1, L3, and $\mathrm{LD}$ ) and specificity (L3-that accommodates specificity pocket) loops contribute to the activation mechanism of HtrA2 through multiple regulatory nodes (Figure 1C). Since these dynamic loops were mostly unresolved in the crystal structure, several efforts were made to investigate the multimodal allosteric regulation of the protease as well as understand the intricacies of HtrA2-mediated substrate cleavage (Martins et al., 2003; Jarzab et al., 2016). Because the 

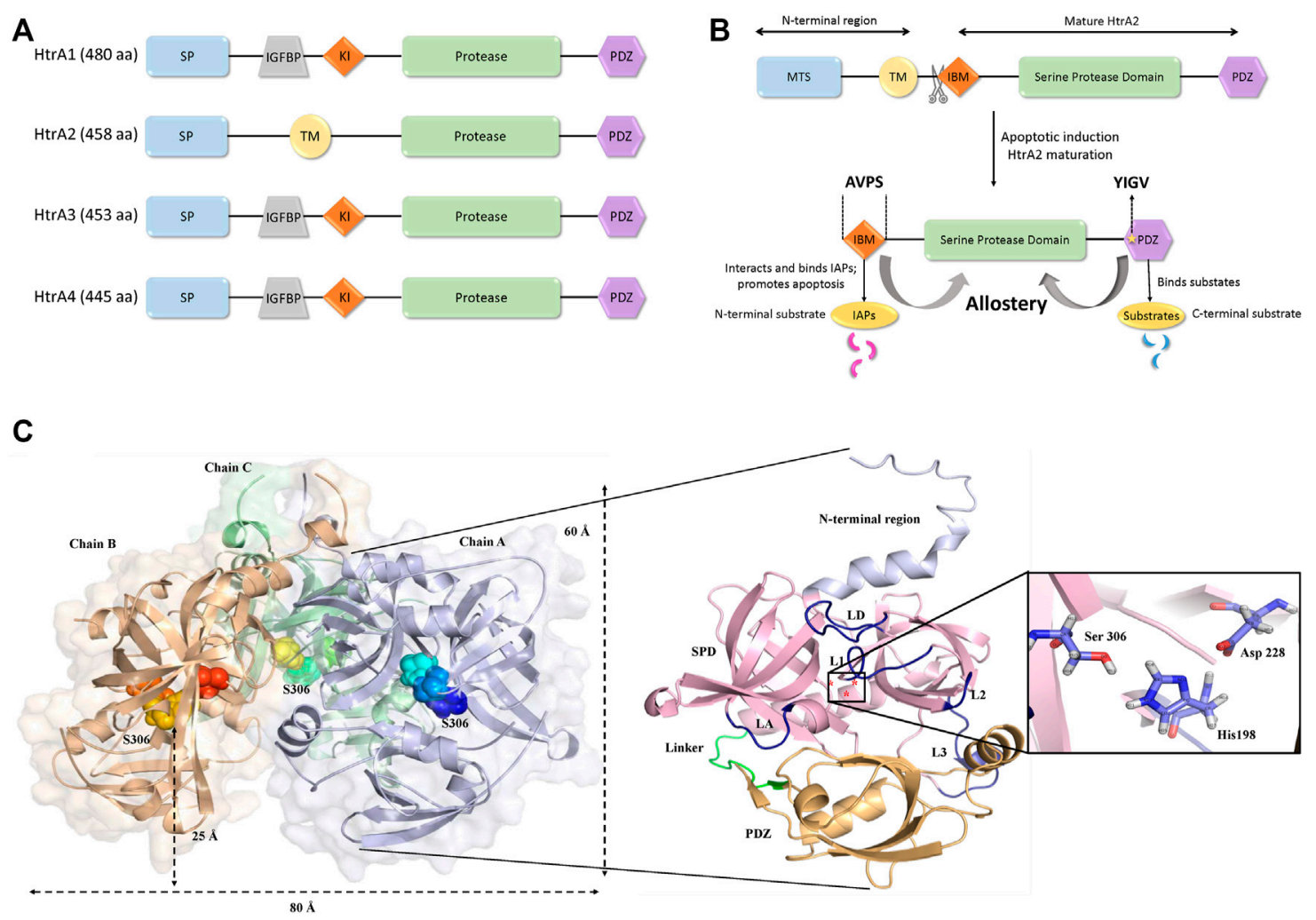

FIGURE 1 | Structural organization of HtrA2. (A) Comparison of domain organizations of the human HtrA family including HtrA1, HtrA2, HtrA3 andHtrA4. aa, amino acid; SP, signal peptide; IGFBP, insulin growth factor binding domain; KI, Kazal-type S protease inhibitor domain; protease, protease domain; PDZ, PDZ domain; TM, transmembrane regulatory domain. (B) Schematic representation of the full-length HtrA2 protein (1-458 aa) and its different components as shown in the figure. Upon apoptotic trigger, the mitochondrial localization signal (133 residues) from the $\mathrm{N}$-terminus gets cleaved exposing a tetrapeptide IAP-binding motif (IBM/AVPS), and concomitantly releasing the protease into the cytosol. Subsequent substrate binding at $\mathrm{N}$ - and/or C-termini leads to allosteric protease activation and substrate cleavage as described in the text. (C) The three-dimensional trimeric model adopted from the crystal structure (PDB ID: 1LCY) of HtrA2 highlighting the hidden catalytic triad (rainbow spheres) $25 \AA$ above base of the pyramid (left side) while a single monomer has been zoomed into for describing the loops (yellow) and domains ( $N$-terminal region: light purple, SPD: pink, PDZ: orange); the catalytic site has been shown in the inset (right side). L1, L2, L3 and LD are loops; SPD is serine protease domain and Linker represents the flexible region between the SPD and PDZ domain.

allosteric binding partners are also predominantly its substrates (such as IAPS, GRIM-19, and Dusp-9), therefore the stepwise concerted allosteric mechanism either individually or in collaboration with different activation pathways could not be unequivocally determined using discrete peptide libraries. To circumvent the problem, Bose and co-workers utilized enzymology and biophysical approaches to understand the intricate coordination between the protease domain and other regions of the protein using full-length binding partners and/or substrates. Using $\beta$-casein, the generic substrate of serine proteases, Chaganti et al., revisited the pre-existing model of HtrA2 activation and propounded a new hypothesis that relies on inter-molecular protease-PDZ crosstalk for initial substrate binding at the PDZ domain and its subsequent cleavage (Chaganti et al., 2013). This study identified interaction between the PDZ domain of one monomer with the serine protease domain of an adjacent one, which led to the rearrangement of $\mathrm{H} 65$ of the catalytic triad in a way to form a proper oxyanion hole. This series of inter-molecular making and breaking of bonds unequivocally demonstrated the requirement of the trimeric architecture for its allosteric propagation and activation by capturing the dynamics of the PDZ- and temperature-mediated activation process. Singh et al., built upon the previous studies on N-terminal mediated activation of HtrA2 (Verhagen et al., 2002) and described the global conformational plasticity and subtle conformational reorientations in the loop regions surrounding the active-site to be involved in this process. Interestingly, using quantitative enzyme kinetics studies, they further demonstrated that the $\mathrm{N}$-terminal mediated activation might also be regulated by PDZ-bound allosteric modulators and vice-versa (Singh et al., 2011; Singh et al., 2014) to bring the protease to the most competent catalytic state.

Although these studies provided a holistic understanding of HtrA's mode of activation through three distinct yet non-exclusive modes, they did not provide the stoichiometric contribution of the PDZ-protease communication in a step-by-step manner. Using molecular dynamics, protein engineering, structural and chemical biology approaches, two different groups (Parui et al., 2021; Toyama et al., 2021) distinctly established the trans-mediated 


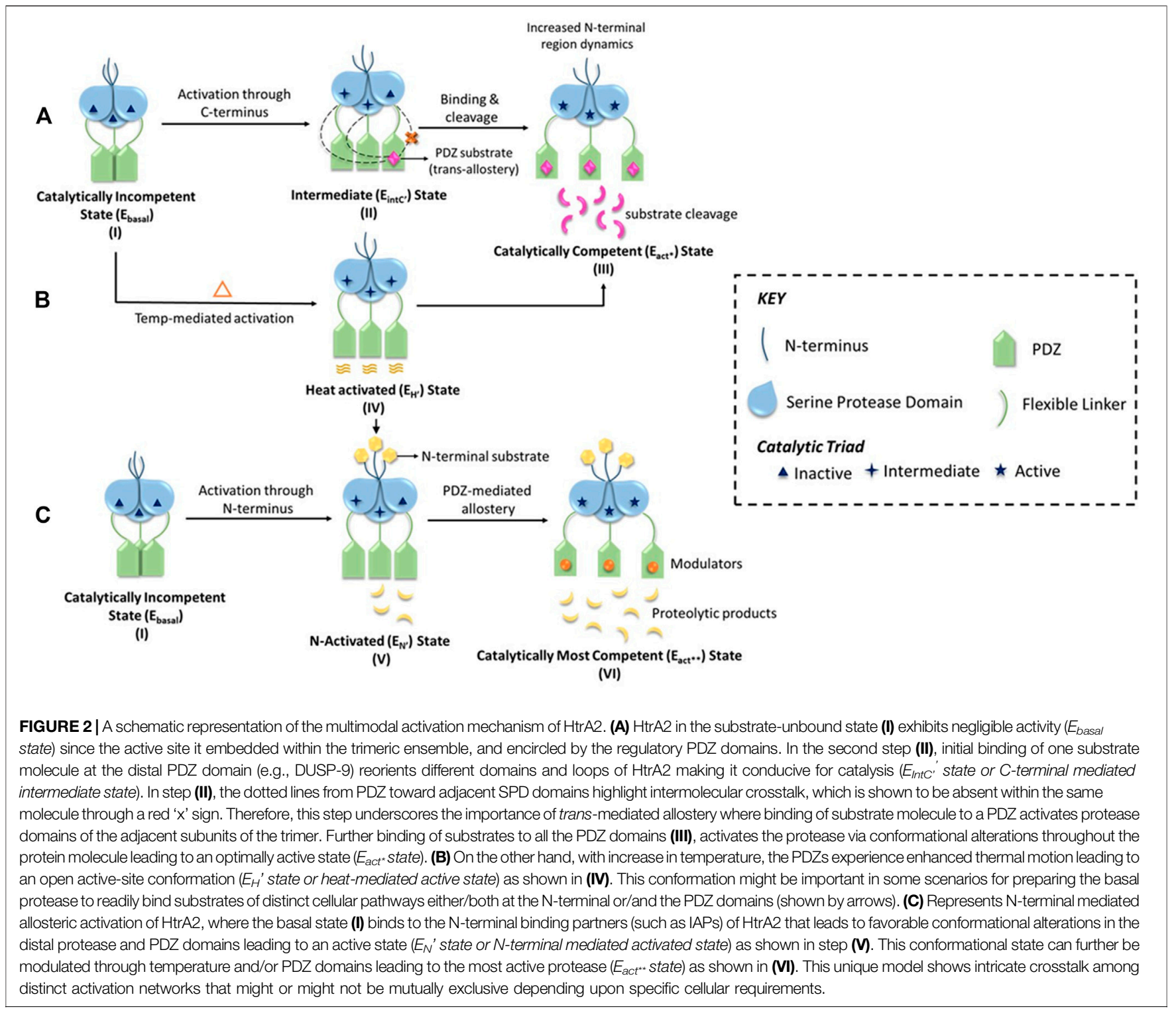

PDZ-protease collaboration that espouses a unique reciprocative mechanism where the distal $\mathrm{PDZ}$ reorients the active site of the adjacent monomer and attunes it for catalysis through a precise synergistic relay of information. This multitiered regulation of HtrA2 activation might be critical toward prevention of untimely proteolysis as well as accurately controlling its involvement in different pathophysiological pathways such as apoptosis, protein quality-control, cancer, arthritis, and neurodegeneration, where it cleaves a wide spectrum of substrates in different subcellular locations. This is substantiated by the identification and characterization of protein-protein interactions involving HtrA2 and its substrates such as Inhibitor of Apoptosis Proteins (IAPs), hematopoietic cell-specific protein-1-(HS1)-associated protein X-1 (Hax-1), Dual-specificity phosphatase-9 (DUSP-9), a gene associated with retinoic and interferon-induced mortality-19 protein (GRIM-19) and Phosphoprotein enriched in astrocytes-15
(Pea-15) (Chaganti et al., 2019; Acharya et al., 2020; Kummari et al., 2021) that unlike other HtrAs are interestingly not restricted to the C-terminal PDZ domains. The holistic enumeration of HtrA2's activation network has been vividly illustrated in Figure $\mathbf{2}$ and the mechanism is elaborated in the figure legend.

This chain of ground-breaking revelations on the reciprocity of its structural dynamism and multifarious physiological as well as disease-associated functions as discussed below have opened up avenues to regulate HtrA2 functions at various check-points toward devising customized therapeutic strategies.

\section{IS HtrA2 A CHAPERONE?}

The neurodegenerative phenotype of mice lacking HtrA2 or harboring the enzymatically inactive mnd2mutant (S276C) 
implies that HtrA2 protease activity protects neuronal mitochondria (Jones et al., 2003; Martins et al., 2004). It was earlier speculated that HtrA2 monitors and regulates protein folding in the mitochondria in a way DegP does in the bacterial periplasm. Further studies demonstrated that unfolded protein response (UPR) induced by tunicamycin or heat shock (Gray et al., 2000) as well as etoposide-activatedp53 stress pathwayupregulated expression of HtrA2 protease (Jin et al., 2003). Alike DegP, HtrA2 is also activated by elevated temperatures (Martins et al., 2003). Moreover, both HtrA2 and DegP prefer aliphatic Val or Ile in $\mathrm{P} 1$ position for substrate recognition and cleavage (Kolmar et al., 1996). Despite these similarities, HtrA2 shares strikingly higher structural and functional traits with DegS, which argue against its DegP-like chaperoning function, and hints a bearing closer to DegS. In particular, HtrA2 is protease-active at room temperature (Savopoulos et al., 2000), while DegP is activated only at elevated temperatures (Spiess et al., 1999). In addition, while DegP with two PDZ domains, folds into a higherorder hexagonal cage (Krojer et al., 2002), the trimeric HtrA2 and DegS (sans the additional PDZ and the necessary longer LA loop) are unable to prevent the entry of correctly folded proteins into the proteolytic sites (Clausen et al., 2002; Kim et al., 2003; Kim and Kim, 2005; Clausen et al., 2011) thus creating certain equivocacies toward defining its role as a chaperone. Interestingly, the identification of presenilin and amyloid precursor protein as natural substrates of HtrA2 (Gray et al., 2000; Gupta et al., 2004) necessitates further studies to resolve the ambiguities surrounding HtrA's role in unfolded protein aggregation and quality control.

\section{ROLE OF HtrA2 IN APOPTOSIS}

HtrA2 was the first to be identified as an IAP binding protein (Hegde et al., 2002). Its functional similarity with second mitochondria-derived activator of caspase (Smac)/direct IAP binding protein with low pI (DIABLO) established its role as a proapoptotic molecule (Martins et al., 2002; Suzuki et al., 2004). HtrA2, which resides in the mitochondrial IMS is released into the cytosol after the separation of its 133-residue mitochondrial localization signal. This exposes an N-terminal IAP-binding motif (IBM) comprising a tetrapeptide 'AVPS' that is recognized as a binding site for IAPs. Unlike Smac, HtrA2 also cleaves IAPs and hence irrevocably relieves their inhibition on caspases (caspases-3,-7, and -9), thus promoting apoptosis (Srinivasula et al., 2003; Yang et al., 2003). Conservation of the IBM motif is found across species, where its Drosophila ortholog with two IBM motifs attracts DIAP1, enabling its removal by the serine protease activity (Challa et al., 2007). Likewise, the rhesus monkey and rodent orthologs of the protease have maintained the IBM motif suggesting evolutionary diversification of HtrA2 functions in higher organisms (Vande Walle et al., 2008). Interestingly, the two IAP-related proteins in C. elegans do not appear to be involved in apoptosis regulation (Fraser et al., 1999; Speliotes et al., 2000), suggesting that IAP proteins and the appearance of IAP antagonists like HtrA2 and Drosophila Reaper, Hid, and Grim are recent additions to the apoptotic molecular repertoire. Although human $\mathrm{HtrA} 2$ and its evolutionary paralogs bind and degrade many IAP family members, $\mathrm{XIAP}$ is found as the most effective amongst them as it engages a second interaction surface that permits strong caspase inhibition (Eckelman et al., 2006). However, to inhibit caspase activation, cIAP1,cIAP2, and XIAP target bound caspases for ubiquitinmediated proteasomal degradation (Vaux and Silke, 2005) thus necessitating HtrA2 to cleave all of them.

Apart from N-terminal mediated apoptosis, HtrA2 binds important molecules of the apoptotic pathway through its regulatory $\mathrm{C}$-terminal $\mathrm{PDZ}$ domain. The binding of substrates to the hydrophobic YIGV groove allosterically activates the protease for substrate binding and subsequent catalysis. Furthermore, binding to mitochondrial substrates at the early apoptotic stage such as GRIM-19 and Hax-1 might be important toward attuning the mature protease for its proapoptotic functions before it enters the cytoplasm (Cilenti et al., 2004; Ma et al., 2007; Chaganti et al., 2019; Kummari et al., 2021) where it binds several antiapoptotic proteins including IAPs and death effector domain (DED) containing Pea-15 (Trencia et al., 2004). HtrA2 is also capable of inducing caspase-independent apoptosis via its serine protease activity by cleaving several critical cellular molecules such as cytoskeletal proteins (actin, $\alpha$ - $/ \beta$-tubulin, and vimentin) that are important for upholding cellular integrity (Vande Walle et al., 2007). KIAA1967 and KIAA0251are two newly identified proteins of the apoptotic pathway that have been found to be substrates of HtrA2 (Vande Walle et al., 2007). A caspase-generated cleavage fragment of KIAA1967 was demonstrated to cause mitochondrial clustering and matrix condensation in apoptotic HeLa cells (Sundararajan et al., 2005), whereas KIAA0251 interacts with the endoplasmic reticulum (ER) membrane protein Bap29, a component known to be required for caspase- 8 activation in the ER (Breckenridge et al., 2002). Taken together, the substrates found and verified for $\mathrm{HtrA} 2$, reveal that this protease is involved in the apoptotic process at the cytoskeleton, translation initiation complex, and organelle dismantling levels.

Multiple modes of activation and a variety of substrates in different subcellular locations make HtrA2 omnipresent in the apoptotic pathway. Furthermore, distal N-/C-termini and heatmediated positive allosteric modulation as well as negative regulation of its proapoptotic functions through phosphorylation at Ser212(Yang et al., 2016) re-instate its enigmatic role in the cell death network. However, the lack of definitive in vivo models of HtrA2's contribution toward apoptotic pathway might be limited by the number of identified natural substrates to date as well as due to redundancy in its functions in the cell, which requires further investigations.

\section{HtrA2 IN NEURODEGENERATIVE DISORDERS AND CANCER}

The first report on HtrA2's involvement in neurodegeneration came into existence with the identification of its interaction with Alzheimer's disease-associated protein, presenilin-1 (Gupta et al., 2004). This was later substantiated by a homozygous loss-of- 
function mutation (S276C) identified as motor neurodegeneration 2 (mnd2) in mice (Jones et al., 2003), which was further bolstered by the development of homozygous HTRA2 knock-out mice exhibiting Parkinsonian phenotype (Martins et al., 2004) thus assigning HTRA2 gene the PARK13(Parkinson's disease 13) locus (Strauss et al., 2005; Abou-Sleiman et al., 2006). These critical inputs led to the initiation of several clinical studies involving PD cohorts from various populations across the globe to identify the involvement of HTRA2 and its mutations in PD progression and pathogenesis. However, the data obtained were quite contrasting. For example, a Germany-based clinical study that demonstrated heterozygous G399S and A141S mutations (Strauss et al., 2005; Bogaerts et al., 2008), was later impugned by another study from North America (Simon-Sanchez and Singleton, 2008). However, in vivo studies in transgenic mice harboring the G399S mutation (Casadei et al., 2016) and several other independent clinical investigations on non-overlapping rare HTRA2 mutations in Asian and European populations, re-established the correlation between HTRA2 gene and PD risk (Bogaerts et al., 2008; Lin et al., 2011; Wang et al., 2011). Furthermore, to delve into the loss of enzymatic activity of S276C mutation in human HtrA2 and correlate it with PD if any, $\mathrm{X}$-ray crystallographic studies of the mutant were performed to understand the structural correlates of this functional repercussion (Wagh and Bose, 2018). The study provided a structural snapshot of the mutant at an atomic resolution where the inactivity was found to be conferred by loss of water-mediated H-bond between residues S276 and I270 on regulatory L2 and LD loops respectively; however, no clinical study could identify S276C mutation in any PD patient. Recently, another patient-derived research in the Indian population identified a rare likely-pathogenic mutation (T242M), which is critical for altering mitochondrial homeostasis due to loss of GSK-3 $\beta$-mediated phosphorylation on HtrA2 leading to uncontrolled cell death with PD phenotype (Bose et al., 2021). Moreover, another contemporary study demonstrates a connection between neuronal death and selective downregulation revealing its link with Huntington's disease (Inagaki et al., 2008).

Despite these crucial discoveries, several contradictory reports challenge the establishment of HtrA2's role in neurodegeneration. This apparent anomaly in these studies might be due to a lack of focus on close interconnections among several parameters that include alterations in HTRA2, mitochondrial functional aberrations, and neurodegeneration. Therefore, future research endeavors encompassing both genetic and epigenetic interactions underlying the complex pathophysiological network of neurodegenerative disorders might provide a more comprehensive picture of HTRA2's association with these diseases.

While the involvement of HtrA1 in cancer is quite prevalent, there have been only a few direct reports of HtrA2's association with oncogenesis. HtrA2 has been found to be widely expressed in several cancer cell lines where over-expression triggered cell death (Suzuki et al., 2001; Martins et al., 2002). Biopsy sample analyses of specific cancers exhibited altered expression of HtrA2 suggesting its role in those cancers. For example, the level of the protease was found to be substantially less in endometrial and ovarian cancer tissues (Narkiewicz et al., 2008; Narkiewicz et al., 2009). On the other hand, higher HtrA2 expression in prostate tumors implicated its association with the differentiation of prostate cancer cells (Hu et al., 2006). Furthermore, elevated levels of HtrA2 in gastric cancers link it with this malignancy (Lee et al., 2003). However, although, the contribution of HtrA2 toward cancer development or regression yet remains to be conclusively elucidated, future studies using multidisciplinary approaches for delineating the HtrA2-associated extensive apoptotic network, and identifying its effect on tumorigenesis might shed more light on this pathophysiological collaboration.

\section{CONCLUDING REMARKS AND FUTURE PERSPECTIVE}

Recent progress in the structural and functional characterization of $\mathrm{HtrA} 2$ has greatly enhanced our understanding of this fascinating protein. Association of this protease with critical cellular functions such as apoptosis, protein quality control, cell growth, and unfolded protein response implicate it in several diseases including neurodegeneration, arthritis, and cancer. Unfortunately, the complexity of its oligomeric structural constitution and mechanism of activation makes it one of the most complex molecules in the HtrA family of proteases. However, recent advancements in deciphering the multi-layered allosteric modulation of HtrA2 from both structural and functional perspectives provide important cues toward targeting its different functions with specific modulators having desired characteristics.

\section{AUTHOR CONTRIBUTIONS}

$\mathrm{KB}, \mathrm{AC}$ and $\mathrm{RB}$ conceived and designed the contents of the review. Manuscript preparation was done by AC, RB and KB. All authors read and approved the manuscript.

\section{FUNDING}

This work is supported by the Department of Biotechnology (DBT), Govt. of India (grant number BT/HRD/NWBA/37/01/ 2015) and intramural research grant received from ACTRECTMC, India (IEC project no. 162).

\section{ACKNOWLEDGMENTS}

The authors thank Shubhankar Dutta for his help with the structure figure and critical inputs on the manuscript. 


\section{REFERENCES}

Abou-Sleiman, P. M., Muqit, M. M. K., and Wood, N. W. (2006). Expanding Insights of Mitochondrial Dysfunction in Parkinson's Disease. Nat. Rev. Neurosci. 7 (3), 207-219. doi:10.1038/nrn1868

Acharya, S., Dutta, S., Mudrale, S. P., and Bose, K. (2020). Dual Specificity Phosphatase 9: A Novel Binding Partner Cum Substrate of Proapoptotic Serine Protease HtrA2. Biochem. Biophysical Res. Commun. 533 (3), 607-612. doi:10.1016/j.bbrc.2020.09.062

Bogaerts, V., Nuytemans, K., Reumers, J., Pals, P., Engelborghs, S., Pickut, B., et al. (2008). Genetic Variability in the Mitochondrial Serine proteaseHTRA2contributes to Risk for Parkinson Disease. Hum. Mutat. 29 (6), 832-840. doi:10.1002/humu.20713

Bose, K., Wagh, A., Mishra, V., Dutta, S., Parui, A. L., Puja, R., et al. (2021). Loss of GSK-3 $\beta$ Mediated Phosphorylation in HtrA2 Contributes to Uncontrolled Cell Death with Parkinsonian Phenotype. Int. J. Biol. Macromolecules 180, 97-111. doi:10.1016/j.ijbiomac.2021.03.040

Breckenridge, D. G., Nguyen, M., Kuppig, S., Reth, M., and Shore, G. C. (2002). The Procaspase- 8 Isoform, procaspase-8L, Recruited to the BAP31 Complex at the Endoplasmic Reticulum. Proc. Natl. Acad. Sci. 99 (7), 4331-4336. doi:10.1073/ pnas.072088099

Casadei, N., Sood, P., Ulrich, T., Fallier-Becker, P., Kieper, N., Helling, S., et al. (2016). Mitochondrial Defects and Neurodegeneration in Mice Overexpressing Wild-type or G399S Mutant HtrA2. Hum. Mol. Genet. 25 (3), 459-471. doi:10. 1093/hmg/ddv485

Chaganti, L. K., Dutta, S., Kuppili, R. R., Mandal, M., and Bose, K. (2019). Structural Modeling and Role of HAX-1 as a Positive Allosteric Modulator of Human Serine Protease HtrA2. Biochem. J. 476 (20), 2965-2980. doi:10. 1042/BCJ20190569

Chaganti, L. K., Kuppili, R. R., and Bose, K. (2013). Intricate Structural Coordination and Domain Plasticity Regulate Activity of Serine Protease HtrA2. FASEB j. 27 (8), 3054-3066. doi:10.1096/fj.13-227256

Challa, M., Malladi, S., Pellock, B. J., Dresnek, D., Varadarajan, S., Yin, Y. W., et al. (2007). Drosophila Omi, a Mitochondrial-Localized IAP Antagonist and Proapoptotic Serine Protease. EMBO J. 26 (13), 3144-3156. doi:10.1038/sj. emboj.7601745

Cilenti, L., Soundarapandian, M. M., Kyriazis, G. A., Stratico, V., Singh, S., Gupta, S., et al. (2004). Regulation of HAX-1 Anti-apoptotic Protein by Omi/HtrA2 Protease during Cell Death. J. Biol. Chem. 279 (48), 50295-50301. doi:10.1074/ jbc.M406006200

Clausen, T., Kaiser, M., Huber, R., and Ehrmann, M. (2011). HTRA Proteases: Regulated Proteolysis in Protein Quality Control. Nat. Rev. Mol. Cel Biol 12 (3), 152-162. doi:10.1038/nrm3065

Clausen, T., Southan, C., and Ehrmann, M. (2002). The HtrA Family of Proteases. Mol. Cel 10 (3), 443-455. doi:10.1016/s1097-2765(02)00658-5

Eckelman, B. P., Salvesen, G. S., and Scott, F. L. (2006). Human Inhibitor of Apoptosis Proteins: Why XIAP Is the Black Sheep of the Family. EMBO Rep. 7 (10), 988-994. doi:10.1038/sj.embor.7400795

Fraser, A. G., James, C., Evan, G. I., and Hengartner, M. O. (1999). Caenorhabditis elegans Inhibitor of Apoptosis Protein (IAP) Homologue BIR-1 Plays a Conserved Role in Cytokinesis. Curr. Biol. 9 (6), 292-302. doi:10.1016/ s0960-9822(99)80137-7

Grau, S., Baldi, A., Bussani, R., Tian, X., Stefanescu, R., Przybylski, M., et al. (2005). Implications of the Serine Protease HtrA1 in Amyloid Precursor Protein Processing. Proc. Natl. Acad. Sci. 102 (17), 6021-6026. doi:10.1073/pnas. 0501823102

Gray, C. W., Ward, R. V., Karran, E., Turconi, S., Rowles, A., Viglienghi, D., et al. (2000). Characterization of Human HtrA2, a Novel Serine Protease Involved in the Mammalian Cellular Stress Response. Eur. J. Biochem. 267 (18), 5699-5710. doi:10.1046/j.1432-1327.2000.01589.x

Gupta, S., Singh, R., Datta, P., Zhang, Z., Orr, C., Lu, Z., et al. (2004). The C-Terminal Tail of Presenilin Regulates Omi/HtrA2 Protease Activity. J. Biol. Chem. 279 (44), 45844-45854. doi:10.1074/jbc.M404940200

Hegde, R., Srinivasula, S. M., Zhang, Z., Wassell, R., Mukattash, R., Cilenti, L., et al. (2002). Identification of Omi/HtrA2 as a Mitochondrial Apoptotic Serine Protease that Disrupts Inhibitor of Apoptosis Protein-Caspase Interaction. J. Biol. Chem. 277 (1), 432-438. doi:10.1074/jbc.M109721200
Hou, J., Clemmons, D. R., and Smeekens, S. (2005). Expression and Characterization of a Serine Protease that Preferentially Cleaves Insulin-like Growth Factor Binding Protein-5. J. Cel. Biochem. 94 (3), 470-484. doi:10.1002/ jcb.20328

Hu, X.-Y., Xu, Y.-M., Chen, X. C., Ping, H., Chen, Z.-H., and Zeng, F.-Q. (2006). Immunohistochemical Analysis of Omi/HtrA2 Expression in Prostate Cancer and Benign Prostatic Hyperplasia. APMIS 114 (12), 893-898. doi:10.1111/j. 1600-0463.2006.apm_271.x

Inagaki, R., Tagawa, K., Qi, M.-L., Enokido, Y., Ito, H., Tamura, T., et al. (2008). Omi/HtrA2 Is Relevant to the Selective Vulnerability of Striatal Neurons in Huntington's Disease. Eur. J. Neurosci. 28 (1), 30-40. doi:10.1111/j.1460-9568. 2008.06323.x

Jarzab, M., Wenta, T., Zurawa-Janicka, D., Polit, A., Gieldon, A. J., Wysocka, M., et al. (2016). Intra- and Intersubunit Changes Accompanying thermal Activation of the HtrA2(Omi) Protease Homotrimer. Biochim. Biophys. Acta (Bba) - Proteins Proteomics 1864 (3), 283-296. doi:10.1016/j.bbapap.2015. 12.002

Jin, S., Kalkum, M., Overholtzer, M., Stoffel, A., Chait, B. T., and Levine, A. J. (2003). CIAP1 and the Serine Protease HTRA2 Are Involved in a Novel P53dependent Apoptosis Pathway in Mammals. Genes Dev. 17 (3), 359-367. doi:10. 1101/gad.1047003

Jones, J. M., Datta, P., Srinivasula, S. M., Ji, W., Gupta, S., Zhang, Z., et al. (2003). Loss of Omi Mitochondrial Protease Activity Causes the Neuromuscular Disorder of Mnd2 Mutant Mice. Nature 425 (6959), 721-727. doi:10.1038/ nature 02052

Kang, S., Louboutin, J.-P., Datta, P., Landel, C. P., Martinez, D., Zervos, A. S., et al. (2013). Loss of HtrA2/Omi Activity in Non-neuronal Tissues of Adult Mice Causes Premature Aging. Cell Death Differ 20 (2), 259-269. doi:10.1038/cdd. 2012.117

Kapri-Pardes, E., Naveh, L., and Adam, Z. (2007). The Thylakoid Lumen Protease Deg1 Is Involved in the Repair of Photosystem II from Photoinhibition in Arabidopsis. Plant Cell 19 (3), 1039-1047. doi:10.1105/tpc.106.046573

Kim, D.-Y., and Kim, K.-K. (2005). Structure and Function of HtrA Family Proteins, the Key Players in Protein Quality Control. BMB Rep. 38 (3), 266-274. doi:10.5483/bmbrep.2005.38.3.266

Kim, D. Y., Kim, D. R., Ha, S. C., Lokanath, N. K., Lee, C. J., Hwang, H.-Y., et al. (2003). Crystal Structure of the Protease Domain of a Heat-Shock Protein HtrA from Thermotoga Maritima. J. Biol. Chem. 278 (8), 6543-6551. doi:10.1074/jbc. M208148200

Kolmar, H., Waller, P. R., and Sauer, R. T. (1996). The DegP and DegQ Periplasmic Endoproteases of Escherichia coli: Specificity for Cleavage Sites and Substrate Conformation. J. Bacteriol. 178 (20), 5925-5929. doi:10.1128/jb.178.20.59255929.1996

Koonin, E. V., and Aravind, L. (2002). Origin and Evolution of Eukaryotic Apoptosis: the Bacterial Connection. Cel Death Differ 9 (4), 394-404. doi:10. 1038/sj.cdd.4400991

Krojer, T., Garrido-Franco, M., Huber, R., Ehrmann, M., and Clausen, T. (2002). Crystal Structure of DegP (HtrA) Reveals a New Protease-Chaperone Machine. Nature 416 (6879), 455-459. doi:10.1038/416455a

Kummari, R., Dutta, S., Patil, S., Mudrale, S. P., and Bose, K. (2021). Elucidating the Role of GRIM-19 as a Substrate and Allosteric Activator of Pro-apoptotic Serine Protease HtrA2. Biochem. J. 478 (6), 1241-1259. doi:10.1042/BCJ20200923

Lee, S. H., Lee, J. W., Kim, H. S., Kim, S. Y., Park, W. S., Kim, S. H., et al. (2003). Immunohistochemical Analysis of Omi/HtrA2 Expression in Stomach Cancer. APMIS 111 (5), 586-590. doi:10.1034/j.1600-0463.2003.1110508.x

Li, W., Srinivasula, S. M., Chai, J., Li, P., Wu, J.-W., Zhang, Z., et al. (2002). Structural Insights into the Pro-apoptotic Function of Mitochondrial Serine Protease HtrA2/Omi. Nat. Struct. Biol. 9 (6), 436-441. doi:10.1038/nsb795

Lin, C.-H., Chen, M.-L., Chen, G. S., Tai, C.-H., and Wu, R.-M. (2011). Novel Variant Pro143Ala in HTRA2 Contributes to Parkinson's Disease by Inducing Hyperphosphorylation of HTRA2 Protein in Mitochondria. Hum. Genet. 130 (6), 817-827. doi:10.1007/s00439-011-1041-6

Lipinska, J., Lapinska-Szumczyk, S., Zurawa-Janicka, D., Skorko-Glonek, J., Emerich, J., and Lipinska, B. (2009). Expression of Human HtrA1, HtrA2, HtrA3 and TGF-B1 Genes in Primary Endometrial Cancer. Oncol. Rep. 21 (6), 1529-1537. doi:10.3892/or_00000385

Ma, X., Kalakonda, S., Srinivasula, S. M., Reddy, S. P., Platanias, L. C., and Kalvakolanu, D. V. (2007). GRIM-19 Associates with the Serine Protease 
HtrA2 for Promoting Cell Death. Oncogene 26 (33), 4842-4849. doi:10.1038/sj. onc. 1210287

Martins, L. M., Iaccarino, I., Tenev, T., Gschmeissner, S., Totty, N. F., Lemoine, N. R., et al. (2002). The Serine Protease Omi/HtrA2 Regulates Apoptosis by Binding XIAP through a Reaper-like Motif. J. Biol. Chem. 277 (1), 439-444. doi:10.1074/jbc.M109784200

Martins, L. M., Morrison, A., Klupsch, K., Fedele, V., Moisoi, N., Teismann, P., et al. (2004). Neuroprotective Role of the Reaper-Related Serine Protease HtrA2/Omi Revealed by Targeted Deletion in Mice. Mol. Cel Biol 24 (22), 9848-9862. doi:10.1128/MCB.24.22.9848-9862.2004

Martins, L. M., Turk, B. E., Cowling, V., Borg, A., Jarrell, E. T., Cantley, L. C., et al. (2003). Binding Specificity and Regulation of the Serine Protease and PDZ Domains of HtrA2/Omi. J. Biol. Chem. 278 (49), 49417-49427. doi:10.1074/jbc. M308659200

Moisoi, N., Klupsch, K., Fedele, V., East, P., Sharma, S., Renton, A., et al. (2009). Mitochondrial Dysfunction Triggered by Loss of HtrA2 Results in the Activation of a Brain-specific Transcriptional Stress Response. Cel Death Differ 16 (3), 449-464. doi:10.1038/cdd.2008.166

Narkiewicz, J., Klasa-Mazurkiewicz, D., Zurawa-Janicka, D., Skorko-Glonek, J., Emerich, J., and Lipinska, B. (2008). Changes in mRNA and Protein Levels of Human HtrA1, HtrA2 and HtrA3 in Ovarian Cancer. Clin. Biochem. 41 (7-8), 561-569. doi:10.1016/j.clinbiochem.2008.01.004

Page, M. J., and Di Cera, E. (2008). Evolution of Peptidase Diversity. J. Biol. Chem. 283 (44), 30010-30014. doi:10.1074/jbc.M804650200

Parui, A. L., Mishra, V., Dutta, S., Bhaumik, P., and Bose, K. (2021). Inter-subunit Crosstalk via PDZ Synergistically Governs Allosteric Activation of Proapoptotic HtrA2. bioRxiv, 2021.2010.2004 2021, 462974. doi:10.1101/2021.10.04.462974

Savopoulos, J. W., Carter, P. S., Turconi, S., Pettman, G. R., Karran, E. H., Gray, C. W., et al. (2000). Expression, Purification, and Functional Analysis of the Human Serine Protease HtrA2. Protein Expr. Purif. 19 (2), 227-234. doi:10. 1006/prep.2000.1240

Simon-Sanchez, J., and Singleton, A. B. (2008). Sequencing Analysis of OMI/ HTRA2 Shows Previously Reported Pathogenic Mutations in Neurologically normal Controls. Hum. Mol. Genet. 17 (13), 1988-1993. doi:10.1093/hmg/ ddn096

Singh, N., D'Souza, A., Cholleti, A., Sastry, G. M., and Bose, K. (2014). Dual Regulatory Switch Confers Tighter Control on HtrA2 Proteolytic Activity. FEBS J. 281 (10), 2456-2470. doi:10.1111/febs.12799

Singh, N., Kuppili, R. R., and Bose, K. (2011). The Structural Basis of Mode of Activation and Functional Diversity: a Case Study with HtrA Family of Serine Proteases. Arch. Biochem. Biophys. 516 (2), 85-96. doi:10.1016/j.abb.2011. 10.007

Speliotes, E. K., Uren, A., Vaux, D., and Horvitz, H. R. (2000). The Survivin-like $C$. elegans BIR-1 Protein Acts with the Aurora-like Kinase AIR-2 to Affect Chromosomes and the Spindle Midzone. Mol. Cel 6 (2), 211-223. doi:10. 1016/s1097-2765(00)00023-x

Spiess, C., Beil, A., and Ehrmann, M. (1999). A Temperature-dependent Switch from Chaperone to Protease in a Widely Conserved Heat Shock Protein. Cell 97 (3), 339-347. doi:10.1016/s0092-8674(00)80743-6

Srinivasula, S. M., Gupta, S., Datta, P., Zhang, Z., Hegde, R., Cheong, N., et al. (2003). Inhibitor of Apoptosis Proteins Are Substrates for the Mitochondrial Serine Protease Omi/HtrA2. J. Biol. Chem. 278 (34), 31469-31472. doi:10.1074/ jbc.C300240200

Strauss, K. M., Martins, L. M., Plun-Favreau, H., Marx, F. P., Kautzmann, S., Berg, D., et al. (2005). Loss of Function Mutations in the Gene Encoding Omi/HtrA2 in Parkinson's Disease. Hum. Mol. Genet. 14 (15), 2099-2111. doi:10.1093/ $\mathrm{hmg} / \mathrm{ddi} 215$

Sundararajan, R., Chen, G., Mukherjee, C., and White, E. (2005). Caspasedependent Processing Activates the Proapoptotic Activity of Deleted in Breast Cancer-1 during Tumor Necrosis Factor-Alpha-Mediated Death Signaling. Oncogene 24 (31), 4908-4920. doi:10.1038/sj.onc.1208681
Suzuki, Y., Imai, Y., Nakayama, H., Takahashi, K., Takio, K., and Takahashi, R. (2001). A Serine Protease, HtrA2, Is Released from the Mitochondria and Interacts with XIAP, Inducing Cell Death. Mol. Cel 8 (3), 613-621. doi:10.1016/ s1097-2765(01)00341-0

Suzuki, Y., Takahashi-Niki, K., Akagi, T., Hashikawa, T., and Takahashi, R. (2004). Mitochondrial Protease Omi/HtrA2 Enhances Caspase Activation through Multiple Pathways. Cel Death Differ 11 (2), 208-216. doi:10.1038/sj.cdd. 4401343

Toyama, Y., Harkness, R. W., Lee, T. Y. T., Maynes, J. T., and Kay, L. E. (2021). Oligomeric Assembly Regulating Mitochondrial HtrA2 Function as Examined by Methyl-TROSY NMR. Proc. Natl. Acad. Sci. USA 118 (11), e2025022118. doi:10.1073/pnas.2025022118

Trencia, A., Fiory, F., Maitan, M. A., Vito, P., Barbagallo, A. P. M., Perfetti, A., et al. (2004). Omi/HtrA2 Promotes Cell Death by Binding and Degrading the Antiapoptotic Protein Ped/pea-15. J. Biol. Chem. 279 (45), 46566-46572. doi:10. 1074/jbc.M406317200

Vande Walle, L., Lamkanfi, M., and Vandenabeele, P. (2008). The Mitochondrial Serine Protease HtrA2/Omi: an Overview. Cel Death Differ 15 (3), 453-460. doi:10.1038/sj.cdd.4402291

Vande Walle, L., Van Damme, P., Lamkanfi, M., Saelens, X., Vandekerckhove, J., Gevaert, K., et al. (2007). Proteome-wide Identification of HtrA2/Omi Substrates. J. Proteome Res. 6 (3), 1006-1015. doi:10.1021/pr060510d

Vaux, D. L., and Silke, J. (2005). IAPs - the Ubiquitin Connection. Cel Death Differ 12 (9), 1205-1207. doi:10.1038/sj.cdd.4401696

Verhagen, A. M., Silke, J., Ekert, P. G., Pakusch, M., Kaufmann, H., Connolly, L. M., et al. (2002). HtrA2 Promotes Cell Death through its Serine Protease Activity and its Ability to Antagonize Inhibitor of Apoptosis Proteins. J. Biol. Chem. 277 (1), 445-454. doi:10.1074/jbc.M109891200

Wagh, A. R., and Bose, K. (2018). Structural Basis of Inactivation of Human Counterpart of Mouse Motor Neuron Degeneration 2 Mutant in Serine Protease HtrA2. Biosci. Rep. 38 (5), BSR20181072. doi:10.1042/ BSR20181072

Wang, C.-y., Xu, Q., Weng, L., Zhang, Q., Zhang, H.-n., Guo, J.-f., et al. (2011). Genetic Variations of Omi/HTRA2 in Chinese Patients with Parkinson's Disease. Brain Res. 1385, 293-297. doi:10.1016/j.brainres.2011.02.037

Yang, L., Sun, M., Sun, X.-m., Cheng, G. Z., Nicosia, S. V., and Cheng, J. Q. (2016). Akt Attenuation of the Serine Protease Activity of HtrA2/Omi through Phosphorylation of Serine 212. J. Biol. Chem. 291 (43), 22843. doi:10.1074/ jbc.A116.700445

Yang, Q.-H., Church-Hajduk, R., Ren, J., Newton, M. L., and Du, C. (2003). Omi/ HtrA2 Catalytic Cleavage of Inhibitor of Apoptosis (IAP) Irreversibly Inactivates IAPs and Facilitates Caspase Activity in Apoptosis. Genes Dev. 17 (12), 1487-1496. doi:10.1101/gad.1097903

Conflict of Interest: The authors declare that the research was conducted in the absence of any commercial or financial relationships that could be construed as a potential conflict of interest.

Publisher's Note: All claims expressed in this article are solely those of the authors and do not necessarily represent those of their affiliated organizations, or those of the publisher, the editors and the reviewers. Any product that may be evaluated in this article, or claim that may be made by its manufacturer, is not guaranteed or endorsed by the publisher.

Copyright ( $\odot 2022$ Chakraborty, Bose and Bose. This is an open-access article distributed under the terms of the Creative Commons Attribution License (CC $B Y$ ). The use, distribution or reproduction in other forums is permitted, provided the original author(s) and the copyright owner(s) are credited and that the original publication in this journal is cited, in accordance with accepted academic practice. No use, distribution or reproduction is permitted which does not comply with these terms. 